\title{
Vesicular Glutamate Transporter-Dependent Glutamate Release from Astrocytes
}

\author{
Vedrana Montana, ${ }^{1}$ Yingchun Ni, ${ }^{1}$ Vice Sunjara, ${ }^{2}$ Xue Hua, ${ }^{1}$ and Vladimir Parpura ${ }^{1}$ \\ ${ }^{1}$ Department of Cell Biology and Neuroscience and Center for Nanoscale Science and Engineering, ${ }^{2}$ International Scholars Program, University of \\ California, Riverside, California 92521
}

\begin{abstract}
Astrocytes exhibit excitability based on variations of their intracellular $\mathrm{Ca}^{2+}$ concentrations, which leads to glutamate release, that in turn can signal to adjacent neurons. This glutamate-mediated astrocyte-neuron signaling occurs at physiological intracellular $\mathrm{Ca}^{2+}$ levels in astrocytes and includes modulation of synaptic transmission. The mechanism underlying $\mathrm{Ca}^{2+}$-dependent glutamate release from astrocytes is most likely exocytosis, because astrocytes express the protein components of the soluble $N$-ethyl maleimide-sensitive fusion protein attachment protein receptors complex, including synaptobrevin 2, syntaxin, and synaptosome-associated protein of 23 $\mathrm{kDa}$. Although these proteins mediate $\mathrm{Ca}^{2+}$-dependent glutamate release from astrocytes, it is not well understood whether astrocytes express functional vesicular glutamate transporters (VGLUTs) that are critical for vesicle refilling. Here, we find in cultured and freshly isolated astrocytes the presence of brain-specific $\mathrm{Na}^{+}$-dependent inorganic phosphate cotransporter and differentiation-associated $\mathrm{Na}^{+}$-dependent inorganic phosphate cotransporter that have recently been identified as VGLUTs 1 and 2. Indirect immunocytochemistry showed a punctate pattern of VGLUT immunoreactivity throughout the entire cell body and processes, whereas pharmacological inhibition of VGLUTs abolished mechanically and agonist-evoked $\mathrm{Ca}^{2+}$-dependent glutamate release from astrocytes. Taken together, these data indicate that VGLUTs play a functional role in exocytotic glutamate release from astrocytes.
\end{abstract}

Key words: astrocytes; vesicular glutamate transporters; SNAREs; V-ATPase; calcium-dependent glutamate release; exocytosis; signaling; synapse

\section{Introduction}

The ultrastructure of the CNS suggests that astrocytes might regulate synaptic neurotransmission. Astrocytes enwrap nerve terminals (Peters et al., 1991), which makes them perfectly positioned to exchange information with synapses. Indeed, it has been demonstrated that astrocytes can respond to synaptic activation (Dani et al., 1992) and that they can modulate synaptic neurotransmission by releasing glutamate in a $\mathrm{Ca}^{2+}$-dependent manner (Araque et al., 1998a; Kang et al., 1998). Because astrocytic internal $\mathrm{Ca}^{2+}$ levels necessary for glutamate release are within the physiological range (Parpura and Haydon, 2000), this

Received Aug. 12, 2003; revised Jan. 30, 2004; accepted Jan. 30, 2004.

This work was supported by a grant from the Department of Defense/Defense Advanced Research Planning Agency/Defense Microelectronics Activity under Award DMEA90-02-2-0216 and the Whitehall Foundation (Award 2000-05-17). V.P. is an Institute for Complex Adaptive Matter Senior Fellow. We thank Dr. Karl Bauer (Max-PlanckInstitute for Experimental Endocrinology, Hannover, Germany) for kindly providing $\beta$-Ala-Lys- $\mathrm{N}_{\epsilon}$-AMCA peptide, Dr. James E. Rothman (Memorial Sloan-Kettering Cancer Center, New York, NY) for generously providing a plasmid encoding for super-ecliptic synapto-pHluorin, and Dr. Robert H. Edwards (University of California San Francisco, San Francisco, (A) for graciously providing polyclonal antibodies against VGLUTs 1 and 3 and plasmids encoding for GST-VGLUTs 1 and 3 fusion proteins. We are grateful for Dr. Glenn I. Hatton's arrangements regarding supply of "Bauer's" peptide and for providing an Alexa Fluor 488 goat anti-mouse antibody. We also thank Dr. Hatton and Todd A. Ponzio for comments on previous versions of this manuscript, for engaging discussions related to this work, and help with brain dissection of adult rats.

Correspondence should be addressed to Dr. Vladimir Parpura, Department of Cell Biology and Neuroscience, 1208 Spieth Hall, University of California, Riverside, CA 92521. E-mail: vlad@citrus.ucr.edu.

V. Sunjara's present address: School of Medicine, University of Zagreb, 10000 Zagreb, Croatia.

DOI:10.1523/JNEUROSCI.3770-03.2004

Copyright $\odot 2004$ Society for Neuroscience $\quad$ 0270-6474/04/232633-10\$15.00/0 release can be used as a signaling pathway that may influence synaptic neurotransmission and plasticity within the CNS.

Although the mechanism of $\mathrm{Ca}^{2+}$-dependent release of glutamate from astrocytes is not fully defined, the protein components of the neuronal exocytotic machinery are expressed in astrocytes (Parpura et al., 1995b; Jeftinija et al., 1997; Bezzi et al., 1998; Hepp et al., 1999; Maienschein et al., 1999; Araque et al., 2000; Pasti et al., 2001). Additionally, Clostridial toxins, which cleave some of these exocytosis-related proteins, inhibit $\mathrm{Ca}^{2+}$ dependent release of glutamate from astrocytes (Jeftinija et al., 1997; Bezzi et al., 1998; Araque et al., 2000), indicating that regulated exocytosis most likely mediates glutamate release from astrocytes.

Immunoelectron microscopic study indicated that exocytotic proteins in astrocytes can be associated with electronlucent or dense-core vesicular structures, the diameters of which are less uniform than those reported in neurons (Maienschein et al., 1999). The storage of glutamate in synaptic vesicles requires the presence of V-type $\mathrm{H}^{+}$-ATPase (V-ATPase) and vesicular glutamate transporters (VGLUTs). Hence, astrocytic $\mathrm{Ca}^{2+}$ dependent glutamate release can be blocked with bafilomycin $\mathrm{A}_{1}$ (Araque et al., 2000; Bezzi et al., 2001; Pasti et al., 2001), which specifically interferes with V-ATPase, leading to alkalinization of vesicular lumen and collapsing the proton gradient necessary for VGLUTs to transport glutamate into vesicles. Brain tissue expresses VGLUT 1 and 2 isoforms (Ni et al., 1994, 1995; Hisano et al., 2000; Bai et al., 2001) in glutamatergic neurons (Bellocchio et 
Table 1. Antibodies raised against VGLUTs and their respective antigens used in this study

\begin{tabular}{|c|c|c|c|c|c|c|c|c|}
\hline \multirow[b]{2}{*}{ Antibody } & \multirow[b]{2}{*}{ Source } & \multirow[b]{2}{*}{ Type } & \multirow{2}{*}{$\begin{array}{l}\text { Catalog number } \\
\text { or reference }\end{array}$} & \multicolumn{2}{|l|}{ Final dilutions } & \multirow[b]{2}{*}{ Adsorption antigen } & \multirow{2}{*}{$\begin{array}{l}\text { Catalog number } \\
\text { or reference }\end{array}$} & \multirow{2}{*}{$\begin{array}{l}\text { Final } \\
\text { concentration } \\
(\mu \mathrm{g} / \mathrm{ml})\end{array}$} \\
\hline & & & & ICC & WB & & & \\
\hline \multirow[t]{3}{*}{ Anti-VGLUT 1} & Synaptic Systems & Mouse monoclonal & 135001 & $1: 1000$ & $1: 1000$ & GST-rVGLUT1 (aа 523-560) & $135-0 P$ & 5 \\
\hline & Synaptic Systems & Rabbit polyclonal & 135002 & $1: 500-1: 1000$ & $1: 1000-1: 2000$ & GST-rVGLUT1 (aа 523-560) & $135-0 P$ & $2.5-5$ \\
\hline & Dr. R. H. Edwards & Rabbit polyclonal ${ }^{a}$ & $\begin{array}{l}\text { Bellocchio et al. } \\
\text { (1998) }\end{array}$ & $1: 500$ & 1:1000 & GST-rVGLUT1 (аa 493-560) & $\begin{array}{l}\text { Bellocchio et al. } \\
\text { (1998) }\end{array}$ & 10.5 \\
\hline \multirow[t]{2}{*}{ Anti-VGLUT 2} & Synaptic Systems & Rabbit polyclonal $^{a}$ & 135102 & $1: 500$ & 1:1000 & GST-rVGLUT2 (aа 510 -582) & 135-1P & $2-5$ \\
\hline & Chemicon & Guinea pig polyclonal & AB5907 & $1: 2000$ & $1: 2000$ & rVGLUT2 (aa 565-582), Sp & AG209 & 2.5 \\
\hline \multirow[t]{2}{*}{ Anti-VGLUT 3} & Chemicon & Guinea pig polyclonal & AB5421 & $1: 5000$ & $1: 5000$ & rVGLUT3 (аa 569-588), Sp ${ }^{b}$ & AG320 & $1-5$ \\
\hline & Dr. R. H. Edwards & Rabbit polyclonal & $\begin{array}{l}\text { Fremeau et al. } \\
\qquad(2002)\end{array}$ & $1: 500$ & 1:1000 & GST-rVGLUT3 (aа 530 -588) & $\begin{array}{l}\text { Fremeau et al. } \\
\qquad(2002)\end{array}$ & 11.5 \\
\hline
\end{tabular}

ICC, Immunocytochemistry; WB, Western blots; GST, glutathione S-tranferase; r, rat; Sp, synthetic peptide. Parentheses indicate the portion of VGLUTs, based on rat amino acid sequences.

${ }^{a}$ No cross-reactivity to VGLUT 3.

${ }^{b}$ Used in cross-reactivity experiments.

al., 1998; Fremeau et al., 2001; Fujiyama et al., 2001; Herzog et al., 2001; Sakata-Haga et al., 2001; Kaneko et al., 2002; Varoqui et al., 2002). Recently, there have been reports indicating the presence of a VGLUT 3 isoform in subpopulations of GABAergic (Fremeau et al., 2002), cholinergic, and monoaminergic neurons (Fremeau et al., 2002; Gras et al., 2002; Schafer et al., 2002) and some astrocytes (Fremeau et al., 2002). However, whether astrocytes can express the VGLUT 1 and 2 isoforms, which account for the release of glutamate by all known excitatory neurons, is not yet known.

In this study, we found the presence of VGLUTs 1 and 2 in cultured and freshly isolated astrocytes from rat visual cortices, exhibiting a subcellular localization pattern consistent with their vesicular association. Because pharmacological inhibition of VGLUTs greatly reduced $\mathrm{Ca}^{2+}$-dependent exocytotic release of glutamate from astrocytes, these proteins can play a functional role in astrocytic glutamate release in the CNS.

Some of these data appeared in preliminary form (Ni et al., 2003)

\section{Materials and Methods}

Cell cultures. We prepared enriched astrocytic cultures using a modification (Parpura et al., 1995a) of the originally described shaking procedure (McCarthy and deVellis, 1980). Visual cortices isolated from 0- to 2-dold Sprague Dawley rats were treated enzymatically (papain, $20 \mathrm{IU} / \mathrm{ml} ; 1$ $\mathrm{hr}$ at $\left.36.8^{\circ} \mathrm{C}\right)$. After subsequent treatment with trypsin inhibitor $(10 \mathrm{mg} /$ $\mathrm{ml}$; type II-O; $5 \mathrm{~min}$ at room temperature) to terminate the enzymatic reaction, tissue was dispersed mechanically by triturating through a glass pipette. Cells were initially plated into tissue culture flasks $\left(25 \mathrm{~cm}^{2}\right)$ and maintained at $36.8^{\circ} \mathrm{C}$ in a humidified $5 \% \mathrm{CO}_{2} / 95 \%$ air atmosphere in a complete culture medium that consisted of $\alpha$-MEM (without phenol red; Invitrogen, Carlsbad, CA) supplemented with $10 \%$ heat-inactivated FBS (HyClone, Logan, UT), L-glutamine (2 mm; Invitrogen), D-glucose (20 mm; Sigma-Aldrich, St. Louis, MO), sodium pyruvate (1 mm; Invitrogen), penicillin $(100 \mathrm{IU} / \mathrm{ml})$, streptomycin $(100 \mu \mathrm{g} / \mathrm{ml})$, and sodium bicarbonate (14 mm; Invitrogen), $\mathrm{pH}$ 7.4.

After 6-24 d in culture, the cells were shaken twice $(260 \mathrm{rpm}$ at $36.8^{\circ} \mathrm{C}$ ), first for $1.5-2 \mathrm{hr}$ and then, after exchange of complete medium, again for 18-20 hr. At that time, the remaining attached cells were detached from flasks using trypsin $\left[10,000 N_{\alpha}\right.$-benzoyl-L-arginine ethyl ester hydrochloride (BAEE) units/ml; Sigma-Aldrich] and replated onto $12 \mathrm{~mm}$ round glass coverslips precoated with polyethyleneimine (PEI; 1 $\mathrm{mg} / \mathrm{ml}$; Sigma-Aldrich). Resulting purified astrocytes were kept in culture for $1-10 \mathrm{~d}(8-29 \mathrm{~d}$ after initial plating) until used in experiments. The purity $(>99 \%)$ of astrocytic culture was confirmed by anti-GFAP antibody and indirect immunocytochemistry. In some experiments before GFAP immunocytochemisty, cells were incubated with a dipeptide $\beta$-Ala-Lys conjugated to 7 -amino-4methylcoumarin-3-acetic acid
(AMCA), kindly provided by Dr. Karl Bauer (Max-Planck-Institute for Experimental Endocrinology, Hannover, Germany). This peptide selectively accumulates in astrocytes after its uptake is mediated by the PepT2 peptide transporter (Dieck et al., 1999). Incubation with $\beta$-Ala-Lys- $\mathrm{N}_{\epsilon^{-}}$ AMCA ( $20 \mu \mathrm{M}$ at $36.8^{\circ} \mathrm{C}$ for $2 \mathrm{hr}$ ) labels astrocytes, because this peptide accumulates only within GFAP-positive cells ( $n=68$ of 68 tested).

Freshly isolated cells. Cells were freshly isolated from visual cortices of 1-, 2-, 8-, and 55-d-old Sprague Dawley rats using a modification of a previously described procedure (Zhou and Kimelberg, 2000). Briefly, visual cortices isolated from rats were subjected to papain treatment, followed by a trituration as described for cell cultures. After trituration, cells were applied onto PEI-coated coverslips and allowed to adhere while they were incubated with $\beta$-Ala-Lys- $\mathrm{N}_{\epsilon}$-AMCA $\left(20 \mu \mathrm{M}\right.$ at $36.8^{\circ} \mathrm{C}$ for 1 $\mathrm{hr}$ ). After washing, cells were fixed for immunocytochemisty.

Immunocytochemistry and nuclear staining. For confirmation of astrocytic culture purity, cells were exposed to Dent's fixative at room temperature for $30 \mathrm{~min}$ (Parpura and Haydon, 2000). A monoclonal antibody (catalog \#69110; 1:500 dilution; $1 \mathrm{hr}$ at room temperature or overnight at $4^{\circ} \mathrm{C}$; ICN Biomedicals, Aurora, $\left.\mathrm{OH}\right)$, followed by a rhodamine-conjugated secondary antibody ( $1 \mathrm{hr}$ at room temperature), was used to probe for GFAP. In some experiments, we subsequently colabeled astrocytic nuclei using 4',6-diamidino-2-phenylindole dilactate (DAPI dilactate; $3 \mu \mathrm{m}$; Molecular Probes, Eugene, OR) for $5 \mathrm{~min}$ at room temperature.

Subcellular localization of VGLUTs 1, 2, and 3, synaptobrevin 2, and synaptosome-associated protein of $23 \mathrm{kDa}$ (SNAP-23) was determined by indirect immunocytochemistry, in which cells were incubated with primary antibodies overnight at $4^{\circ} \mathrm{C}$. A monoclonal antibody against synaptobrevin 2 (catalog \#104201; 1:250 dilution; Synaptic Systems, Goettingen, Germany), a polyclonal antibody against SNAP-23 (catalog \#111202; 1:50; Synaptic Systems), and seven different antibodies against VGLUTs (Table 1) were used. After washout of the primary antibody, TRITC (rhodamine)-conjugated secondary antibodies were applied, and preparation was incubated for $1 \mathrm{hr}$ at room temperature. In doublelabeling experiments, an Alexa Fluor 488-conjugated secondary antibody (Molecular Probes) was used for visualization of synaptobrevin $2 \mathrm{immu}-$ noreactivity. In all experiments, we performed controls in which primary antibodies were omitted to test for nonspecific binding of secondary antibodies. We classified cells as immunoreactive if the average fluorescence intensity for a probed protein, within a cellular region of interest (at least $40 \times 40$ pixels), was at least 2 SDs above the average signals acquired from control cells. In a subset of experiments, we performed adsorption controls, in which primary antibodies were preincubated overnight at $4^{\circ} \mathrm{C}$ with respective antigens, proteins, or peptides (Table 1 ), to test for specificity of primary antibodies (Bellocchio et al., 1998; Fremeau et al., 2001, 2002; Takamori et al., 2001). All imaging data were background subtracted using fluorescence emission originating from a region on the coverslip containing no cells.

Preparation of subcellular fractions and Western blotting. Synaptosomal 

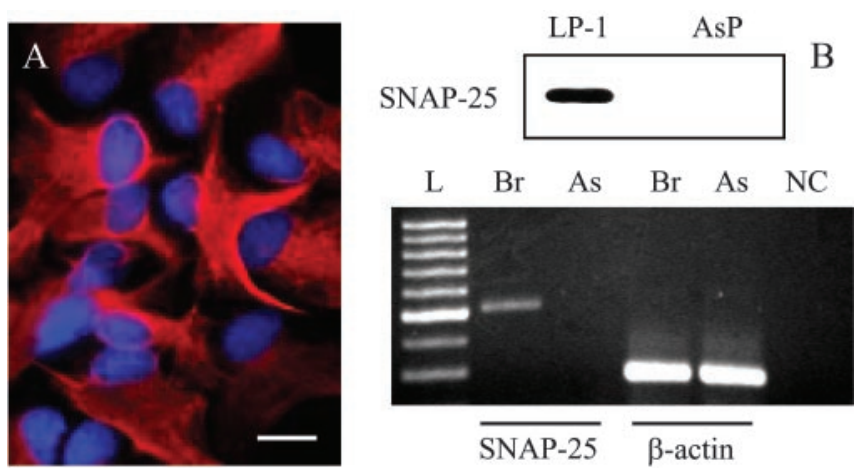

Figure 1. Purified astrocytic cultures are immunopositive for GFAP but do not express SNAP25. $A$, GFAP was used to identify astrocytes (red), with nuclei that are counterstained with DAP (blue). B, Top, After SDS-PAGE (1 $\mu$ g per lane for LP-1 and $15 \mu$ g per lane for AsP), immunoblots indicate the absence of SNAP- 25 in the astrocytic non-nuclear cell membrane extract AsP, while this protein was detected in synaptosomal membrane-enriched LP-1 preparations. Bottom, RT-PCR using mRNA isolated from purified astrocytes (As) reveals the presence of $\beta$-actin and lack of SNAP-25 PCR products. $\beta$-Actin and SNAP-25 PCR products (285 and 521 bp, respectively) were present when $m R N A$ isolated from rat brain (Br) was used in RT-PCR. L represents a molecular size marker (100 bp DNA ladder), whereas NC represents a negative control for reaction. Scale bar, $20 \mu \mathrm{m}$.

membrane-enriched [lysate pellet (LP-1)] preparations were done according to the standard procedures (Huttner et al., 1983). We obtained non-nuclear membranes and vesicular extracts from purified astrocytes [astrocytic preparation (AsP)] as described previously (Parpura et al., 1995b). LP-1 and AsP were subjected to 15\% SDS-PAGE, followed by transfer to nitrocellulose membranes that were probed with VGLUT antibodies used in immunocytochemistry, but at different dilutions (Table 1), and antibodies against synaptobrevin 2 and SNAP-23, which we used at 1:1000 and 1:400, respectively. Additionally, we used monoclonal antibodies against SNAP-25 (catalog \#111001; 1:500; Synaptic Systems) and syntaxin 1 (catalog \#S0664; 1:1000; Sigma-Aldrich). Immunoreactivity of bands was detected using ECL (Amersham Biosciences, Piscataway, NJ). In a subset of experiments, we performed adsorption controls for primary antibodies against VGLUTs (Table 1) as described for immunocytochemistry (Bellocchio et al., 1998; Fremeau et al., 2001, 2002; Takamori et al., 2001). In experiments testing for cross-reactivity of antibodies raised against VGLUTs 1 and 2 to their heterologous VGLUT 3 antigen, we preincubated different VGLUT antibodies with VGLUT 3 antigen.

Reverse transcription-PCR. Total RNA was extracted from purified astrocytic culture and cortical tissue of postnatal Sprague Dawley rats $(0-$ 2-d-old) using TRIzol Reagent (Invitrogen) and protocols provided by the manufacturer. Five micrograms of total RNA were used for reverse transcription using Oligo(dT) ${ }_{12-18}$ and superscript II reverse transcriptase (Invitrogen). Several pairs of primers were used to amplify cDNA using PCR (each pair, 35 cycles). Primers for SNAP-25A (GenBank accession number L19760) amplification were $5^{\prime}$-CTGGAAAGCACCCGTCGTATG-3' and $5^{\prime}$-GCACGTTGGTTGGCTTCATCA-3', whereas for $\beta$-actin the primers were $5^{\prime}$-TCATGAAGTGTGACGTTGACATCCGT- ${ }^{\prime}$ ' and $5^{\prime}$-CCTAGAAGCATTTGCGGTGCACGATG-3' (catalog \#G5740; Promega, Madison, WI). In some experiments, we used two rounds of amplification for SNAP25A (GenBank accession number NM_030991). In the first round, we used 5'-ATGGCCGAGGACGCAGACA-3' and 5'-ACCACTTCCCAGCATCTTTGT-3' (618 bp product). Amplified DNA was used as the template for the second round of PCR using nested primers $5^{\prime}$-CTGGAAAGCACCCGTCGCATG-3' and 5'-GCACGTTGGTTGGCTTCATCA-3' (521 bp product). RT-PCR reaction in two subsequent rounds was also performed for VGLUT 2 (GenBank accession number NM_053427) using 5' AGCAAGGTTGGCATGTTGTCTG-3' and 5'-CGGTCCTTATAGGAGTACGCGT-3' (698 bp product), followed by amplification of the product using nested primers $5^{\prime}$-TGGTGCAATGACGAAGAACAAG-3' and 5'TCC TTTTTCTCCCAGCCGTT-3' (294 bp product). Primers for VGLUT 1 (GenBank accession number NM_053859) amplification were 5'-
GAGAAACAGCCGTGGGCAGAG-3' and 5'-TCAGTAGTCCCGGACAGGGGGTGG-3' (207 bp product), whereas for VGLUT 3 (GenBank accession number NM_153725) the primers were $5^{\prime}$-ACCCGGGAAGAATGGCA GAATGTG-3' and 5' -ATGGGAAAAGCAATGGGTGTGGAG-3' (399 bp product).

Calcium measurements. We monitored astrocytic intracellular $\mathrm{Ca}^{2+}$ levels using a $\mathrm{Ca}^{2+}$ indicator, fluo-3 (Parpura et al., 1994). Cells were loaded in a complete culturing medium containing an acetoxymethyl (AM) ester derivative of fluo-3 (10 $\mu \mathrm{g} / \mathrm{ml}$; Molecular Probes) and pluronic acid $\left(0.025 \% \mathrm{w} / \mathrm{v}\right.$; Molecular Probes), at $36.8^{\circ} \mathrm{C}$ for $30 \mathrm{~min}$. After washing in normal external solution, de-esterification of the dye was permitted for $30 \mathrm{~min}$ at room temperature. The normal external solution contained (in mM) $140 \mathrm{NaCl}, 5 \mathrm{KCl}, 2 \mathrm{CaCl}_{2}, 2 \mathrm{MgCl}_{2}, 5$ glucose, and 10 HEPES, pH 7.4. Coverslips containing fluo-3-loaded cells were mounted into a recording chamber and imaged. All data were background subtracted and expressed as $d F / F$ o (percentage), where Fo represents the fluorescent level before cell stimulation, and $d F$ represents the change in fluorescence.

Glutamate measurements. We optically monitored extracellular glutamate levels using an L-glutamate dehydrogenase (GDH; Sigma-Aldrich)linked assay (Bezzi et al., 1998; Innocenti et al., 2000). GDH generates $\mathrm{NADH}$ from $\mathrm{NAD}^{+}(\beta$-nicotinamide adenine dinucleotide; SigmaAldrich) in the presence of glutamate. Provided that GDH and $\mathrm{NAD}^{+}$ are added to the solution in which astrocytes are bathed, glutamate released in the extracellular space can be detected as an increase in NADH fluorescence. Astrocytes were bathed in an enzymatic assay solution containing normal external solution supplemented with $\mathrm{NAD}^{+}(1 \mathrm{~mm})$ and GDH ( $\sim 53 \mathrm{IU} / \mathrm{ml}$; pH 7.4). Every experiment was preceded by a sham run on cells bathed in solution lacking GDH and $\mathrm{NAD}^{+}$, which was used to correct for photobleaching and background subtraction. The reduction of fluorescence because of photobleaching in the sham run exhibited the same time course as in the matching experimental run. All imaging data, corrected for photobleaching and background subtracted, were expressed as $d F / F o$ (percentage).

Transfection. After the purification of astrocytes, cells in flasks were transfected with a plasmid encoding for super-ecliptic synapto-pHluorin (Sankaranarayanan et al., 2000), kindly provided by Dr. James E. Rothman (Memorial Sloan-Kettering Cancer Center, New York, NY), each flask receiving $6 \mu \mathrm{g}$ of plasmid premixed with $12 \mu \mathrm{l}$ of TransIT-293 transfection reagent (catalog \#2700; Mirus, Madison, WI), which aids plasmid entry to cells for 3-4 hr. At that time, we replaced culturing medium and returned cells to the culture incubator. Cells were maintained at $36.8^{\circ} \mathrm{C}$ in a humidified $5 \% \mathrm{CO}_{2} / 95 \%$ air atmosphere for $2 \mathrm{~d}$, when they were replated onto PEI-coated coverslips and kept in culture until used in experiments.

Imaging acquisition and processing. All experiments were done at room temperature $\left(20-24^{\circ} \mathrm{C}\right)$. We used an inverted microscope (TE 300; Nikon, Melville, NY) equipped with wide-field epifluorescence. Visualization of indirect immunocytochemistry of GFAP, VGLUTs, and SNARE proteins was accomplished using a standard rhodamine/TRITC filter set (Chroma Technology, Rockingham, VT), except in double-labeling experiments in which immunoreactivity of synaptobrevin 2 was visualized using a standard fluorescein/FITC filter set (Chroma Technology), whereas for nuclear staining (DAPI) and $\beta$-Ala-Lys- $\mathrm{N}_{\epsilon}$-AMCA we used a standard DAPI filter set (Chroma Technology). For calcium imaging and synapto-pHluorin, we used a standard fluorescein/FITC filter set. Images were captured through a $60 \times$ plan-achromatic oil-immersion objective [numerical aperture (NA), 1.4; Nikon) using either a CoolSNAP-HQ cooled CCD camera (Roper Scientific, Tucson, AZ) or an intensified CCD camera (IC-300; Photon Technology International, Lawrenceville, $\mathrm{NJ}$ ) driven by $\mathrm{V}++$ imaging software (Digital Optics, Auckland, New Zealand) or LabView/IMAQ (National Instruments, Austin, TX), respectively. For glutamate imaging experiments, we used a $40 \times$ SFluor objective (NA, 1.3; Nikon) and a DAPI filter set (Chroma Technology). For time-lapse image acquisition, a camera and an electronic shutter (Vincent Associates, Rochester, NY) inserted in the excitation pathway were controlled by software. A Xenon arc lamp (100 W) was used as a light source. In a subset of double-labeling experiments, we used a C1 modular confocal microscope system (Nikon) configured with an in- 


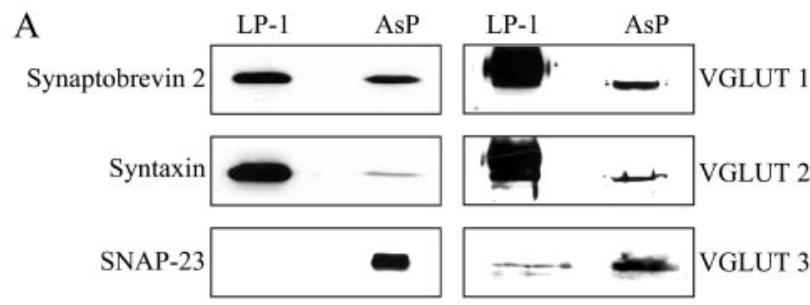

B

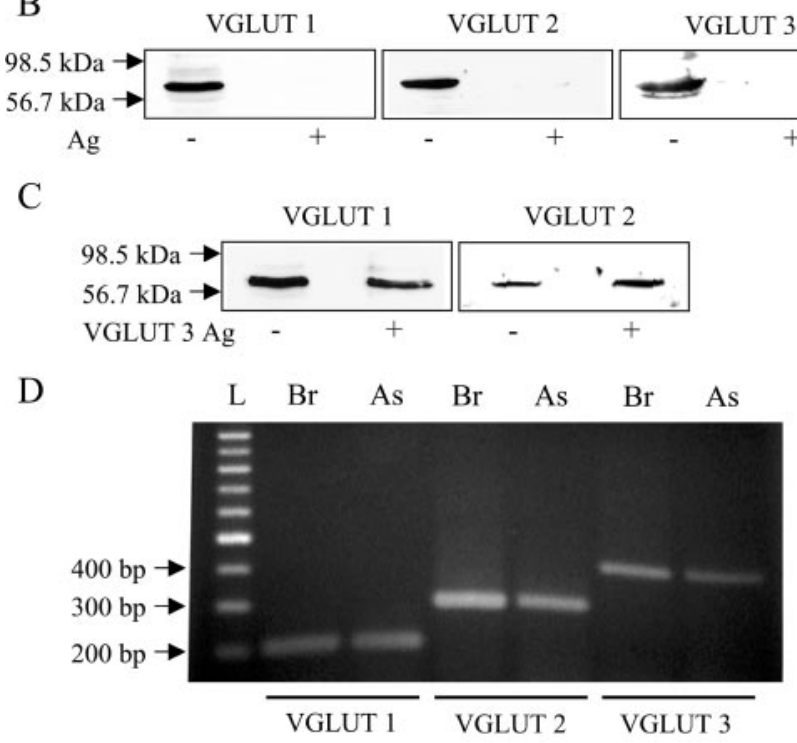

Figure 2. Astrocytes in culture express VGLUTs 1 and 2. A, After SDS-PAGE, immunoblots indicate the presence of VGLUTs 1, 2, and 3 in astrocytes (AsP) as well as SNARE proteins, synaptobrevin 2, syntaxin, and SNAP-23. In LP-1 preparations, SNAP-23 was not detected. When probing SNARE proteins, LP-1 was loaded 1-2 $\mu \mathrm{g}$ per lane, whereas AsP was loaded $10-15 \mu \mathrm{g}$ per lane. However, when probing VGLUTs, LP-1 and AsP were equally loaded at 15 $\mu \mathrm{g}$ per lane for VGLUTs 1 and 2 or $30 \mu \mathrm{g}$ per lane for VGLUT 3. B, The immunoreactive bands in AsP recognized by antibodies raised against VGLUT 1,2 , and 3 isoforms ( $\mathrm{Ag}-$ ) were completely abolished when antibodies were preincubated with their homologous antigens $(\mathrm{Ag}+)$. C, Antibodies raised against VGLUTs 1 and 2 do not cross-react with VGLUT 3 because their preadsorption with this heterologous antigen does not abolish the immunoreactive bands, although the same VGLUT 3 antigen in preadsorption with anti-VGLUT 3 , as seen in $B$, abolishes its ability for detection. The arrows in $B$ and $C$ indicate molecular weight markers. D, RT-PCR using mRNA isolated from purified astrocytes (As) or from brain (Br) reveals the presence of VGLUT 1, 2, and 3 PCR products (207, 294, and 399 bp, respectively). $L$ and arrows indicate molecular size markers (100 bp DNA ladder).

verted microscope (TE 2000; Nikon) and equipped with a VioFlame Plus solid state laser (405 nm; for DAPI and AMCA excitation), an argon laser (488 nm; for Alexa Fluor 488 excitation; Melles Griot, Carlsbad, CA) and a Spectra Physics green helium neon laser $(543 \mathrm{~nm}$; for TRITC excitation). All images shown in the figures represent raw data.

Stimulation of astrocytes. To evoke an increase in the internal $\mathrm{Ca}^{2+}$ concentrations in astrocytes and consequential glutamate release, we either bath applied agonists (duration, $55 \mathrm{sec}$ ) bradykinin ( $90 \mathrm{~nm}$ ) and ATP $(9 \mu \mathrm{M})$ or mechanically stimulated astrocytes using patch pipettes (Parpura et al., 1994; Araque et al., 2000). To control the establishment of the contact between the pipette and an astrocyte, we monitored pipette resistance during delivery of $-20 \mathrm{mV}, 10 \mathrm{msec}$ square pulses by a patchclamp amplifier (PC-ONE; Dagan, Minneapolis, MN) equipped with a whole-cell headstage (PC-ONE-30; 1 G $\Omega$ ). Pipette resistances measured 2.3-3.3 $\mathrm{M} \Omega$ when pipette tips were immersed in an external solution, which increased to $2.7-4.0 \mathrm{M} \Omega(7-21 \%$ increase) during transient contacts with astrocytes, lasting $<1 \mathrm{sec}$.

Pharmacological agents. In experiments using a $\mathrm{Ca}^{2+}$ chelator, BAPTA, cells were loaded in a complete culturing medium containing BAPTA-AM (50 $\mu \mathrm{M}$; Molecular Probes) and pluronic acid $(0.025 \% \mathrm{w} / \mathrm{v})$
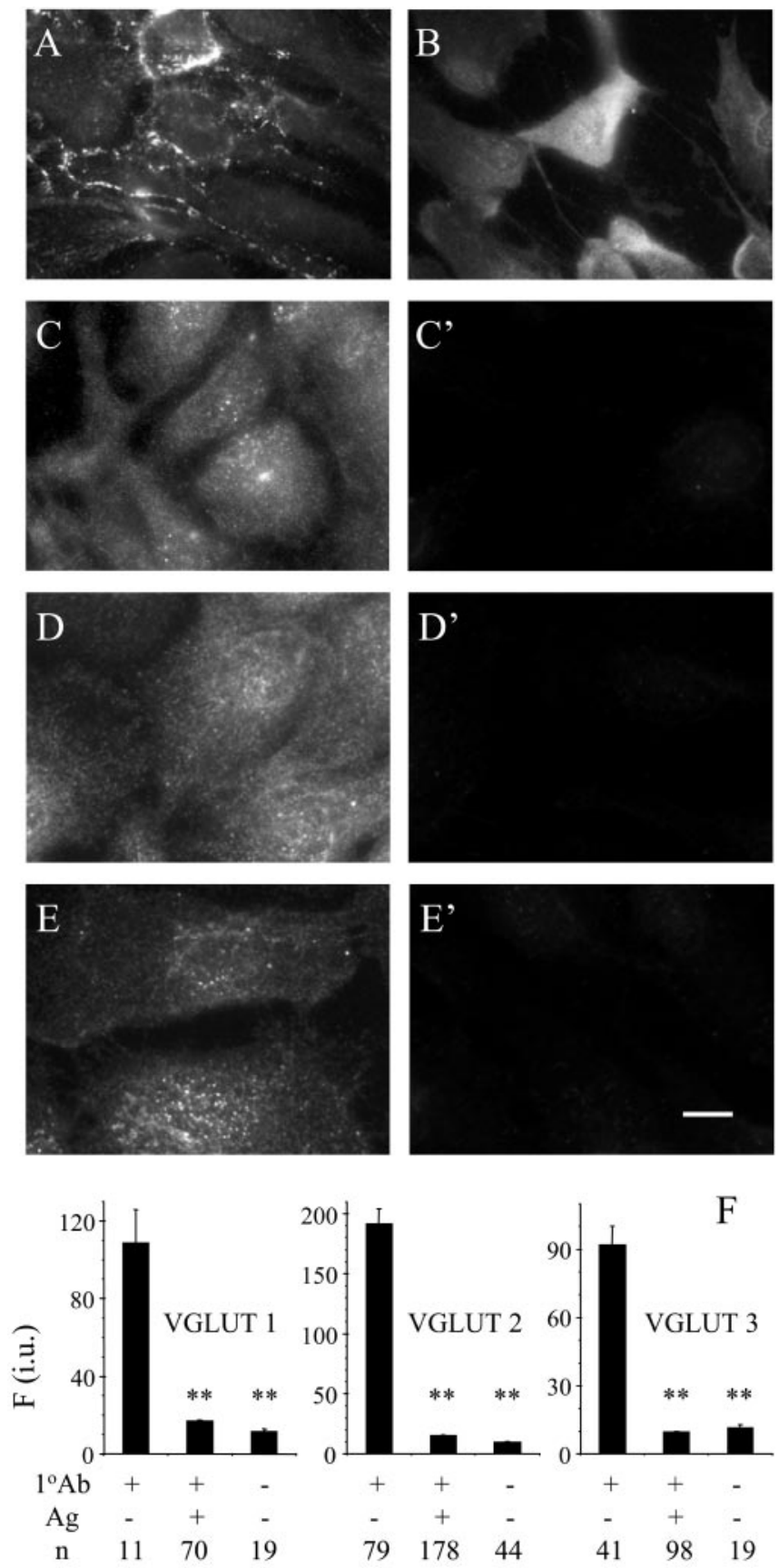

Figure 3. Subcellular localization of synaptobrevin 2 (A), SNAP-23 (B), VGLUT 1 (C), VGLUT $2(D)$, and VGLUT $3(E)$. VGLUT immunoreactivity was completely abolished when primary antibodies $\left(1^{\circ} \mathrm{Ab}\right)$ were preadsorbed with their respective antigens $(\mathrm{Ag})$ in cultured astrocytes $\left(C^{\prime}-E^{\prime}, F\right)$. Scale bar: $A, B, 20 \mu \mathrm{m} ; C-E, C^{\prime}-E^{\prime}, 10 \mu \mathrm{m}$. Fluorescent immunoreactivity is expressed in intensity units (i.u.). Bars represent means \pm SEMs of measurements from the number of individual astrocytes ( $\mathrm{n})$. Asterisks indicate a significant change of measurements compared with the control group $\left(1^{\circ} \mathrm{Ab}+, \mathrm{Ag}-\right.$; one-way ANOVA, followed by post hoc Fisher's LSD test; $\left.{ }^{* *} p<0.01\right)$. We found no difference between measurements in preadsorption controls $\left(1^{\circ} \mathrm{Ab}+, \mathrm{Ag}+\right)$ when compared with controls in which primary antibodies were omitted $\left(1^{\circ} \mathrm{Ab}-, \mathrm{Ag}-\right)$.

at $36.8^{\circ} \mathrm{C}$ for $30 \mathrm{~min}$. After washing in normal external solution, deesterification of the chelator was permitted for $30 \mathrm{~min}$ at room temperature before use of cells in imaging experiments. Holoprotein of tetanus toxin (15 $\mu \mathrm{g} / \mathrm{ml}$; List Biological Laboratories, Campbell, CA) was applied to the cells in a complete culturing medium for $24-48 \mathrm{hr}$ at $36.8^{\circ} \mathrm{C}$, at which time cells were rinsed three times with an external solution and used in imaging experiments. Astrocytes were preincubated with bafilo- 

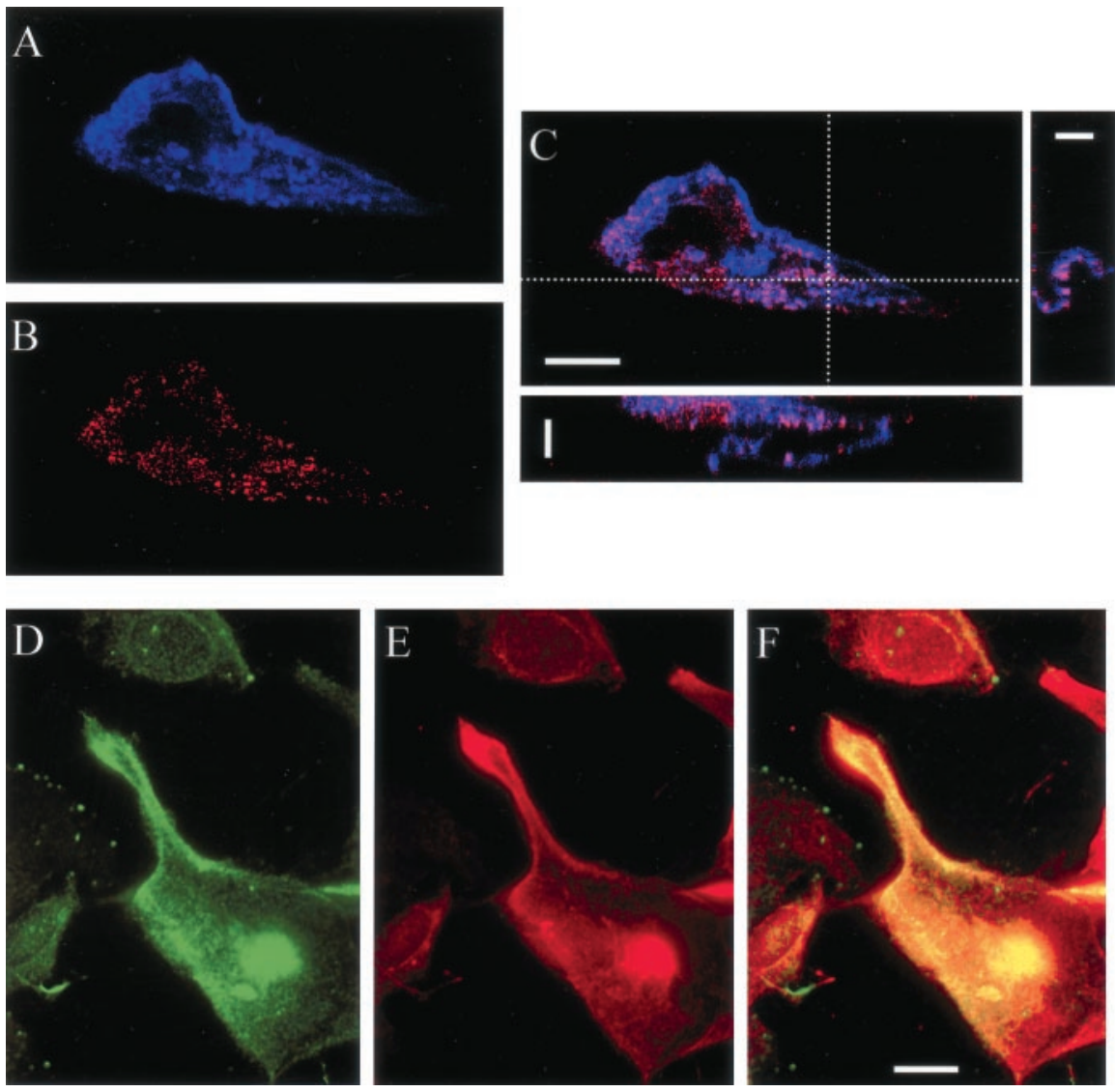

Figure 4. VGLUT immunoreactivity colocalizes with vesicular marker synaptobrevin 2. A, Astrocytes were identified based on their ability to intracellularly accumulate $\beta$-Ala-Lys- $\mathrm{N}_{\epsilon}$-AMCA (blue). Double labeling using indirect immunocytochemistry against VGLUT 2 ( $B$; red) reveals punctate immunoreactivity that colocalizes with $\beta$-Ala-Lys- $\mathrm{N}_{\epsilon}-\mathrm{AMCA}$ ( $C$; overlay of $A$ and $B$; pink indicates colocalization), as shown in X-Z ( $C$; bottom) and Y-Z (C; right) projections from the regions identified by dotted lines. Double labeling of astrocytes with synaptobrevin $2(D ;$ green) and a mixture of antibodies labeling all three isoforms of VGLUTS ( $E$; red) indicates that VGLUT immunoreactivity substantially overlaps with vesicular marker synaptobrevin 2 ( $F$; overlay of $D$ and $E$; yellow indicates colocalization). Scale bars: $C, X-Z$ and $Y$-Z projections, $5 \mu \mathrm{m} ; A-C, 10 \mu \mathrm{m} ; D-F, 20 \mu \mathrm{m}$.

mycin $A_{1}(5 \mu \mathrm{M} ; 30$ or 60 min; Sigma-Aldrich) and Rose Bengal (0.1 or $0.5 \mu \mathrm{M} ; 30 \mathrm{~min}$; Sigma-Aldrich) at room temperature.

Statistical analysis. The effect of agonists and mechanical stimulation on intracellular $\mathrm{Ca}^{2+}$ levels and consequential glutamate release, as well as the effects of Rose Bengal on synapto-pHluorin fluorescence, were assessed using a paired $t$ test. When testing the time-dependent effects of bafilomycin $\mathrm{A}_{1}$ on synapto-pHluorin fluorescence, we used a paired $t$ test with Bonferroni adjustment for multiple comparisons. The effects of pharmacological agents on glutamate and $\mathrm{Ca}^{2+}$ measurements, as well as the effects of preadsorption of primary antibodies with respective antigens on VGLUT immunoreactivity, were determined using one-way ANOVA, followed by Fisher's least significant difference (LSD) test. Student's $t$ test was used for assessing the effects of Rose Bengal on ATP- or bradykinin-induced $\mathrm{Ca}^{2+}$ increases and glutamate release.

\section{Results}

Differential interference contrast microscopy of astrocyteenriched cultures indicated that these cultures were neuron free. This was confirmed using indirect immunocytochemistry, immunoblotting, and RT-PCR. Astrocytic cell cultures were immunopositive for GFAP (245 of 245 cells tested), a characteristic astrocytic marker, revealing the purity of this culture to be $>99 \%$ (Fig. 1A). To assess the extent of putative neuronal contamination, we used immunoblots and RT-PCR. We prepared a nonnuclear membrane extract from cultured astrocytes (AsP) that was subjected to SDS-PAGE (Fig. $1 B$, top). We used synaptoso-

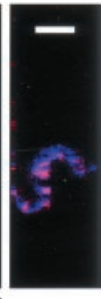

mal plasma membrane-enriched preparation (LP-1) as a positive control. Immunoblot analysis revealed the absence of a neuron-specific protein, SNAP-25 (Parpura et al., 1995b; Latour et al., 2003), in astrocytic culture, although SNAP-25 was reliably detected in LP-1 preparations. Next, we performed RT-PCR using mRNA isolated from rat brain and from astrocytic cultures (Fig. $1 B$, bottom). The PCR product for SNAP-25 was not detected in astrocytic mRNA, whereas the positive control was obtained from brain mRNA. Taken together, immunocytochemisty, Western blots, and RT-PCR demonstrate that the cultures used in this study were devoid of neurons and contain GFAP-positive polygonal astrocytes.

To determine for the presence of VGLUTs 1 and 2, we submitted AsP and LP-1 to SDS-PAGE, followed by Western blots (Fig. 2A). We found that astrocytic preparations showed expression of VGLUTs 1 and 2 and also VGLUT 3, the presence of which had been recently reported in astrocytes in vivo (Fremeau et al., 2002). VGLUTs 1 and 2 were much less abundant in AsP than in LP-1, whereas VGLUT3 was more abundant in AsP. Additionally, astrocytes contained SNARE proteins, synaptobrevin 2, syntaxin, and SNAP-23 (Parpura et al., 1995b; Hepp et al., 1999). To assess the specificity of antibodies raised against VGLUTs (Table 1), we first performed preadsorption controls (Fig. 2B). We subjected AsP to the SDSPAGE, followed by Western blot analysis using antibodies alone or antibodies that were preincubated with their respective antigens (Table 1). We detected VGLUTs only when probing with antibodies alone but not in preadsorption controls. Next, we performed controls for cross-reactivity of antibodies raised against VGLUTs 1 and 2 to a VGLUT 3 antigen (Fig. 2C). Lack of cross-reactivity of anti-VGLUTs 1 and 2 to VGLUTs 2 and 1, respectively, had been demonstrated previously (Bellocchio et al., 1998; Takamori et al., 2001), but not their possible crossreactivity to VGLUT 3. Because astrocytes in vivo express VGLUT 3 , it is possible that the antibodies we used against VGLUTs 1 and 2 cross-react with VGLUT 3 . To address this issue, we preincubated antibodies against VGLUTs 1, 2, and 3 with a VGLUT 3 antigen. We used antibodies alone or preincubated antibodies to probe membranes containing AsP. We found that preadsorption with VGLUT 3 antigens abolished VGLUT detection on Western blots only when using anti-VGLUT $3(-99 \%$ of control; $n=3$ ) but not for anti-VGLUT $1(+32 \%$ of control; $n=3)$ and antiVGLUT $2(+11 \%$ of control; $n=3)$, indicating that these antibodies to not exhibit cross-reactivity to VGLUT 3 (Fig. 2C). After assessment of the antibody specificity, we performed RT-PCR using $\mathrm{mRNA}$ isolated from rat brain and from astrocytic cultures (Fig. 2D). PCR products for VGLUTs 1, 2, and 3 were detected in astrocytic mRNA. Thus, Western blots and RT-PCR demonstrate that the purified astrocytic cultures express all three known isoforms of VGLUTs. 

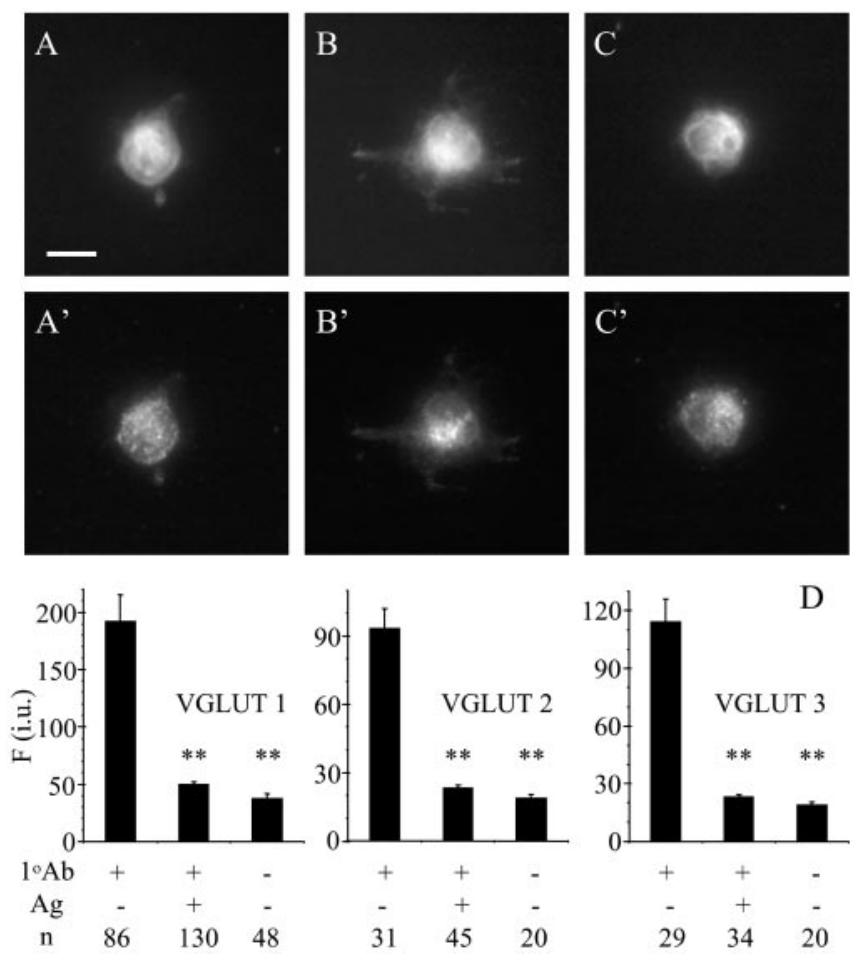

Figure 5. Freshly isolated astrocytes contain VGLUTs. $A-C$, Astrocytes were identified based on their ability to accumulate $\beta$-Ala-Lys- $\mathrm{N}_{\epsilon}$-AMCA. Double labeling using indirect immunocytochemistry against VGLUT1 $\left(A^{\prime}\right)$, VGLUT2 $\left(B^{\prime}\right)$, or VGLUT $3\left(C^{\prime}\right)$ revealed punctate immunoreactivity that was completely abolished $(D)$ when primary antibodies $\left(1^{\circ} \mathrm{Ab}\right)$ were preadsorbed with their respective antigens $(\mathrm{Ag}+)$. Fluorescent immunoreactivity is expressed in intensity units (i.u.). Bars represent means \pm SEMs of measurements from a number of individual freshly isolated astrocytes ( $\mathrm{n}$ ). Asterisks indicate a significant change of measurements compared with the control group $\left(1^{\circ} \mathrm{Ab}+, \mathrm{Ag}-\right.$; one-way ANOVA, followed by post hoc Fisher's LSD test; $\left.{ }^{* *} p<0.01\right)$. We found no difference between measurements in preadsorption controls $\left(1^{\circ} \mathrm{Ab}+, \mathrm{Ag}+\right)$ when compared with controls in which primary antibodies were omitted $\left(1^{\circ} \mathrm{Ab}-, \mathrm{Ag}-\right)$. Scale bar, $10 \mu \mathrm{m}$.

Table 2. Expression of VGLUTs 1, 2, and 3 in cultured and freshly isolated (FIA) astrocytes

\begin{tabular}{|c|c|c|c|c|}
\hline \multirow{2}{*}{$\begin{array}{l}\text { Astrocytes } \\
\text { Animal age (days) }\end{array}$} & \multirow{2}{*}{$\frac{\text { Cultured }}{0-1}$} & \multicolumn{3}{|c|}{ FIA } \\
\hline & & $1-2$ & 8 & 55 \\
\hline \multicolumn{5}{|l|}{ VGLUT 1} \\
\hline Tested & 335 & 156 & 22 & 22 \\
\hline Positive & 316 & 134 & 16 & 7 \\
\hline Percentage positive & 94 & 86 & 73 & 32 \\
\hline \multicolumn{5}{|l|}{ VGLUT 2} \\
\hline Tested & 404 & 113 & 25 & 26 \\
\hline Positive & 381 & 112 & 17 & 9 \\
\hline Percentage positive & 94 & 99 & 68 & 35 \\
\hline \multicolumn{5}{|l|}{ VGLUT 3} \\
\hline Tested & 144 & 74 & 19 & 22 \\
\hline Positive & 136 & 55 & 10 & 9 \\
\hline Percentage positive & 94 & 74 & 53 & 41 \\
\hline
\end{tabular}

The intracellular localization of proteins was studied using indirect immunocytochemistry (Fig. 3). Staining with antiVGLUT 1 (Fig. 3C), anti-VGLUT 2 (Fig. 3D), or anti-VGLUT 3 (Fig. $3 E$ ) showed a punctate pattern of immunoreactivity that was present throughout the entire cell body and processes, and it was completely abolished when antibodies were preadsorbed with their respective antigens (Fig. $3 C^{\prime}-E^{\prime}, F$ ). However, consistent with Western blot data, staining of astrocytes with anti-VGLUT 1 $(n=68)$ or anti-VGLUT $2(n=46)$ showed no reduction in fluorescence intensities, when these antibodies were preincubated with a VGLUT3 antigen. A similar pattern of punctate immunoreactivity was observed using anti-SNAP-23 (Fig. 3B). Synaptobrevin 2, however, was primarily located at the leading edge of the cells, although there were puncta present throughout the entire cell body (Figs. 3A, 4D).

To further study intracellular distribution of VGLUTs, we used double labeling. First, we used $\beta$-Ala-Lys- $\mathrm{N}_{\epsilon}$-AMCA (Dieck et al., 1999) (also see Materials and Methods) to label astrocytes, followed by colabeling using indirect immunocytochemistry against VGLUTs 1, 2, or 3. In Figure 4, we show a typical distribution of VGLUT 2 immunoreactivity that colocalizes with intracellular astrocytic tag $\beta$-Ala-Lys- $\mathrm{N}_{\epsilon}$-AMCA, as revealed by volume rendering after image acquisition using a laser confocal scanning microscope (Fig. 4A-C). Similar distributions were observed for colabeling VGLUT 1 or 3 with $\beta$-Ala-Lys- $\mathrm{N}_{\epsilon}$-AMCA, indicating predominant intracellular, rather than plasma membrane, association of VGLUTs. Because VGLUTs show synaptic vesicular localization in neurons, next we used indirect immunocytochemisty to label astrocytic vesicular pool using a synaptic vesicle marker synaptobrevin 2, while counterstaining VGLUTs using a mixture of antibodies encompassing all three isoforms (Fig. 4D-F). We found a substantial colocalization of VGLUTs with synaptobrevin 2, although some of the synaptobrevin 2 immunoreactivity was devoid of VGLUT immunoreactivity. Because astrocytes, in addition to glutamate, can exocytotically release ATP (Coco et al., 2003) and atrial natriuretic peptide (Krzan et al., 2003), this is possibly attributable to vesicular packaging of these segretagogues in the absence of intravesicular glutamate, hence some synaptobrevin 2-positive vesicles lacking VGLUTs.

Because astrocytes could de-differentiate while cultured, possibly leading to gene expression of VGLUTs, we next used freshly (acutely) isolated astrocytes that provide information of properties without the changes in gene expression (Kimelberg et al., 2000a,b, 2001). Astrocytes were freshly isolated from rat visual cortices of 1-, 2-, 8-, and 55-d-old rats. To determine the identity of astrocytes in cell mixture, we used $\beta$-Ala-Lys- $\mathrm{N}_{\epsilon}$-AMCA. We colabeled cells using indirect immunocytochemistry against either VGLUT 1, VGLUT 2, or VGLUT 3. Once we localized astrocytes of interest based on their ability to accumulate $\beta$-Ala-Lys$\mathrm{N}_{\epsilon}$-AMCA (Fig. 5A-C), we checked for expression of VGLUTs in these cells. We found that freshly isolated astrocytes contained VGLUTs in a punctate pattern similar to that seen in cultured astrocytes (Fig. $5 A^{\prime}-C^{\prime}$ ). This immunoreactivity was completely abolished when antibodies were preadsorbed with their respective antigens (Fig. 5D) but not in astrocytes probed with antiVGLUT $1(n=54)$ or anti-VGLUT $2(n=56)$ antibodies when these antibodies were preincubated with a VGLUT 3 antigen. The positive immunoreactivity exhibited fluorescence intensity that was five (for VGLUTs 1 and 2) to six (for VGLUT 3) times higher than the intensity recorded from control astrocytes in which primary antibodies were omitted. This signal/noise ratio may indicate that the expression of VGLUTs in freshly isolated astrocytes is low. The proportion of astrocytes expressing VGLUTs declined with the increased age of the animals (Table 2). Together, these data demonstrate that astrocytes express VGLUTs.

Having determined that astrocytes in culture as well as freshly isolated astrocytes possess VGLUTs, we asked whether VGLUTs play a role in $\mathrm{Ca}^{2+}$-dependent exocytotic release of glutamate from astrocytes. We optically monitored glutamate release into extracellular space surrounding cultured astrocytes using GDHlinked assay, based on accumulation of the fluorescent product $\mathrm{NADH}$. To evoke $\mathrm{Ca}^{2+}$-dependent glutamate release from astro- 

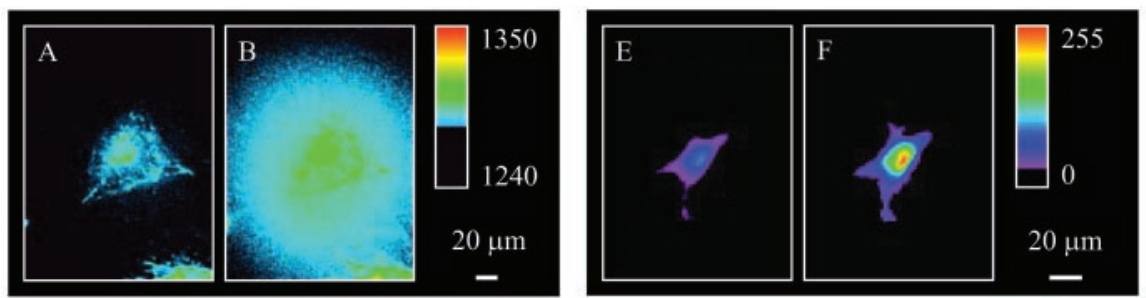

$\mathrm{C}$
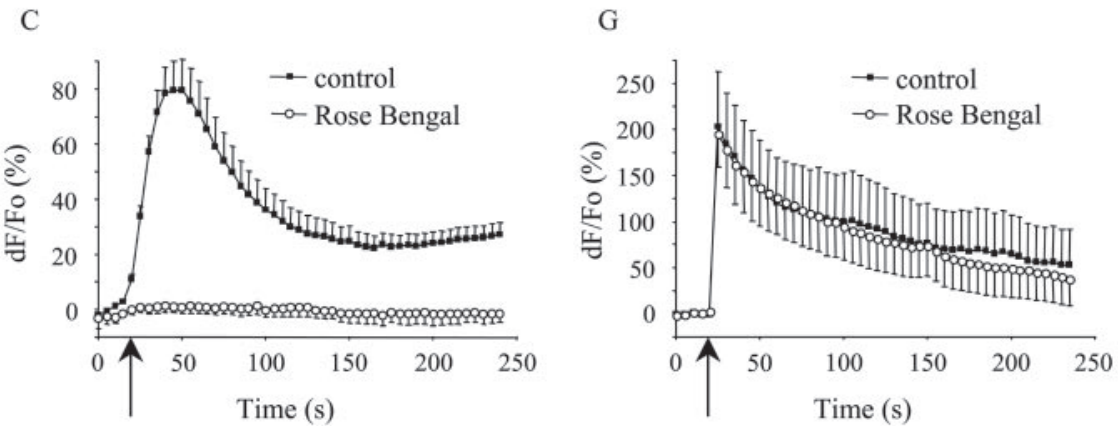

$\mathrm{D}$

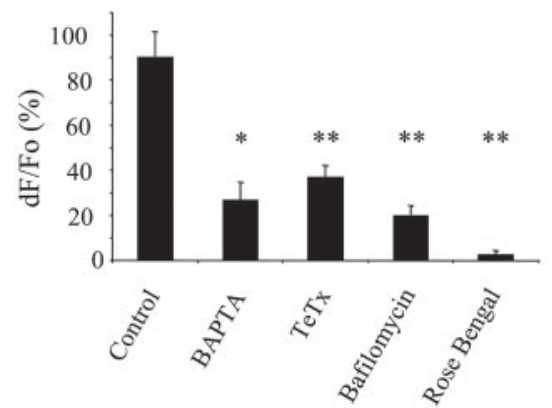

$\mathrm{H}$

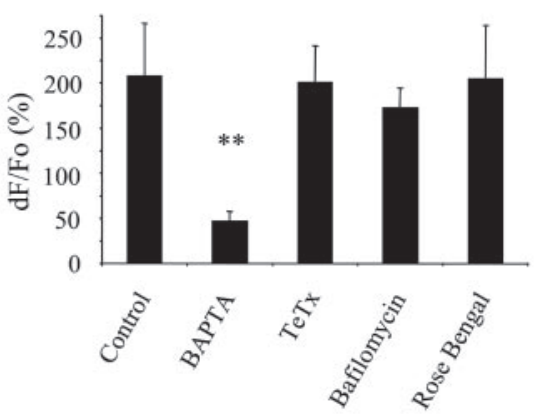

Figure 6. VGLUTs mediate exocytotic glutamate release from cultured astrocytes. Mechanical stimulation evokes glutamate release $(A-D)$ caused by the internal $\mathrm{Ca}^{2+}$ elevations in astrocytes $(E-H)$. Glutamate release from astrocyte is shown (raw data) in $A$ (rest) and $B$ (after stimulation). The pseudocolor scale is a linear representation of the fluorescence intensities ranging from 1240 to 1350 . C, Time lapse of NADH fluorescence, reporting on glutamate release. Mechanical stimulation caused glutamate release (black squares) that was greatly reduced when cells were preincubated with Rose Bengal (open circles; $0.5 \mu \mathrm{m} ; 30 \mathrm{~min}$ ), an allosteric site modulator of VGLUTs. D, Peak values of mechanically induced glutamate release. Incubation of astrocytes with BAPTA-AM (50 $\mu \mathrm{m} ; 30 \mathrm{~min})$, a membrane-permeable $\mathrm{Ca}^{2+}$ chelator, reduced the mechanically induced glutamate release. Pretreatment of astrocytes with a holoprotein of tetanus toxin (TeTx; $15 \mu \mathrm{g} / \mathrm{ml} ; 24-48 \mathrm{hr}$ ), which cleaves synaptobrevin 2, or bafilomycin $\mathrm{A}_{1}(5 \mu \mathrm{M}, 1 \mathrm{hr})$, a specific inhibitor of V-ATPase, reduces mechanically induced glutamate release consistent with exocytotic mechanism underlying $\mathrm{Ca}^{2+}$-dependent glutamate release from astrocytes. Changes in NADH fluorescence are shown as $d F / F o$ (percentage) after background subtraction and correction for bleaching. $E-H$, In experiments parallel to those in $A-D$, astrocytes were mechanically stimulated while measuring intracellular $\mathrm{Ca}^{2+}$ levels using fluo-3. This stimulation reliably increases the intracellular $\mathrm{Ca}^{2+}$ levels $(F)$ from its resting level $(E)$ (raw data). The pseudocolor scale is a linear representation of the fluorescence intensities ranging from 0 to 255. G, Time lapse of fluo-3 fluorescence, reporting on $\mathrm{Ca}^{2+}$ levels in astrocytes. Mechanical stimulation caused an increase in astrocytic intracellular $\mathrm{Ca}^{2+}$ levels (black squares) that were unaffected when cells were preincubated with Rose Bengal (open circles; $0.5 \mu \mathrm{m} ; 30 \mathrm{~min}$ ). $\mathrm{H}$, Peak values of mechanically induced $\mathrm{Ca}^{2+}$ elevations are greatly reduced when cells are preincubated with BAPTA but not when treated with TeTx, bafilomycin $\mathrm{A}_{1}$, or Rose Bengal. Changes in fluo-3 fluorescence are expressed as $d F / F o$ (percentage) after background subtraction. Arrows $(C, G)$ indicate the time when the pipette-astrocyte contact occurred. Points and bars represent the means and SEMs. In C and G, SEMs are shown in single directions for clarity. Asterisks indicate a significant change of measurements compared with the control group (one-way ANOVA, followed by post hoc Fisher's LSD test; ${ }^{*} p<0.05 ;{ }^{* *} p<0.01$ ). We found no significant difference between various treatments in $D$, whereas in $H$, preincubation with BAPTA, in addition to a significant change in measurement compared with the control group, showed a statistically significant difference when compared with all other treatments $(p<0.05)$.

cytes, we used mechanical stimulation, known to cause an increase in astrocytic intracellular $\mathrm{Ca}^{2+}$ levels (Nedergaard, 1994; Araque et al., 1998a), leading to glutamate release (Parpura et al., 1994; Araque et al., 1998a). To apply mechanical stimulus, we established a contact between an astrocyte and a patch pipette under control of a patch-clamp amplifier. This direct stimulation reliably caused glutamate release from astrocytes as indicated by a transient increase in NADH fluorescence surrounding astrocytes (Fig. 6A-D) (control group, $n=41$; peak response $d F / F o=90 \pm 12 \%$; paired $t$ test; $p<0.01)$.

We confirmed the $\mathrm{Ca}^{2+}$ and SNARE dependency of this glutamate release (Parpura et al., 1994, 1995a,b; Jeftinija et al., 1997; Bezzi et al., 1998; Araque et al., 2000; Parpura and Haydon, 2000; Pasti et al., 2001). We monitored the intracellular $\mathrm{Ca}^{2+}$ levels using the $\mathrm{Ca}^{2+}$ indicator fluo-3. Mechanical stimulation caused transient $\mathrm{Ca}^{2+}$ elevations (Fig. $6 \mathrm{E}-\mathrm{H}$ ) (control group, $n=7$; peak response $d F$ / $F o=208 \pm 58 \%$; paired $t$ test; $p<0.015$ ), which was greatly reduced when we preincubated astrocytes with BAPTA-AM (50 $\mu \mathrm{M}$; $30 \mathrm{~min}$; $23 \%$ of control; $n=8$; peak response $d F / F o=47+11 \%$; Fisher's LSD; $p<0.01$ ) (Fig. 6H). Consistent with $\mathrm{Ca}^{2+}$ dependency of mechanically induced glutamate release, this $\mathrm{Ca}^{2+}$ chelator greatly reduced the extracellular NADH fluorescence accumulation reporting on glutamate release ( $29 \%$ of control; $n=4$; peak response $d F / F o=26 \pm 8 \%$; Fisher's LSD test; $p<0.05$ ) (Fig. 6D).

Growing evidence indicates that the mechanism underlying the $\mathrm{Ca}^{2+}$. dependent glutamate release from astrocytes is exocytosis (Jeftinija et al., 1997; Bezzi et al., 1998; Araque et al., 2000; Pasti et al., 2001). Consequently, we tested the sensitivity of mechanically induced glutamate release from astrocytes to tetanus toxin and bafilomycin $\mathrm{A}_{1} \cdot \mathrm{Ca}^{2+}$. dependent glutamate release from astrocytes can be reduced when astrocytes are exposed to tetanus toxin that specifically cleaves synaptobrevin 2 (Jeftinija et al., 1997; Bezzi et al., 1998; Pasti et al., 2001). We confirmed the presence of synaptobrevin 2 (Parpura et al., 1995b) in astrocytes using Western blots (Fig. 2) and indirect immunocytochemistry (Fig. 3). Additionally, we tested functional involvement of synaptobrevin 2 in $\mathrm{Ca}^{2+}$-dependent glutamate release from astrocytes by pretreating these cells with holoprotein of tetanus toxin $(15 \mu \mathrm{g} / \mathrm{ml}$ for $24-48 \mathrm{hr})$. After incubation with this toxin, astrocytes had reduced ability to release glutamate in response to mechanical stimulation $(41 \%$ of control; $n=13$; peak response $d F / F o=$ $37 \pm 5 \%$; Fisher's LSD test; $p<0.01$ ) (Fig $6 D)$, although toxin treatment did not affect mechanically induced $\mathrm{Ca}^{2+}$ elevations (Fig. $\left.6 H\right)(n=6)$.

Bafilomycin $A_{1}$, a specific inhibitor of V-ATPase (Bowman et al., 1988), has been shown to reduce the extent of $\mathrm{Ca}^{2+}$. dependent glutamate release from astrocytes, by collapsing the proton gradient necessary for vesicular storage of glutamate 


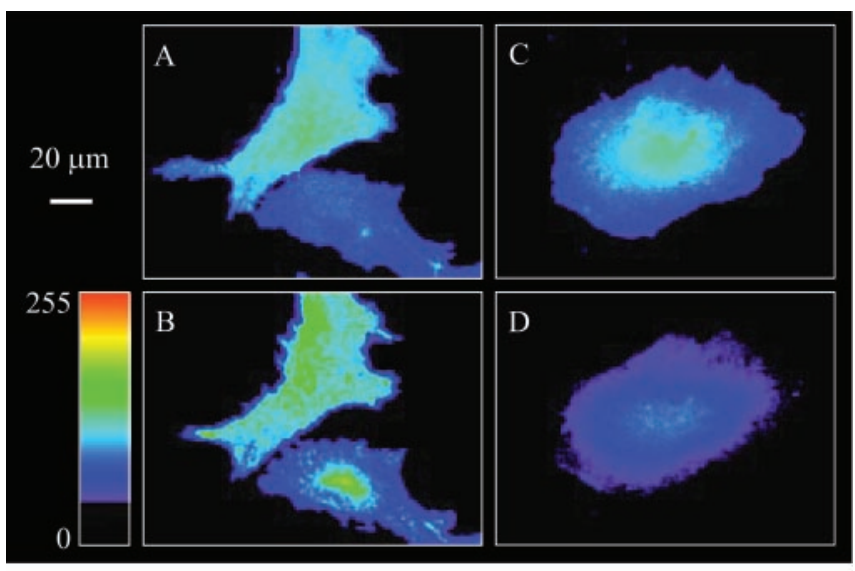

E

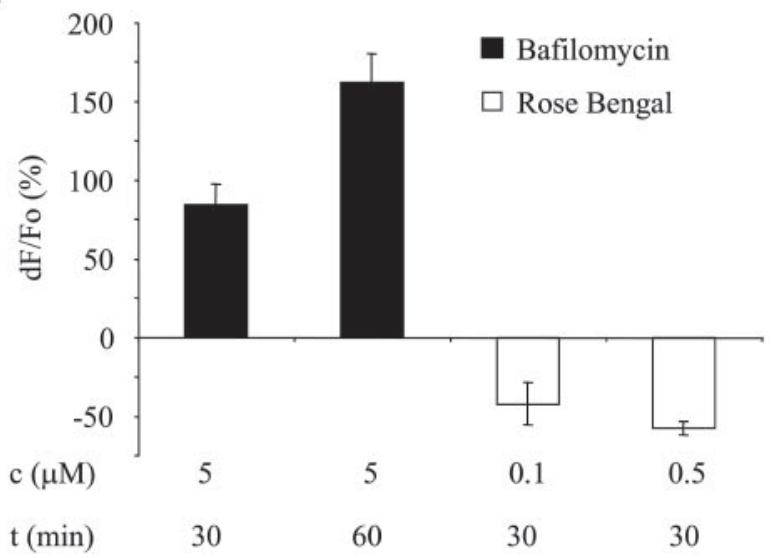

Figure 7. Bafilomycin $A_{1}$ alkalinizes vesicular lumen, whereas Rose Bengal acidifies it, consistent with the actions of these agents on V-ATPase and VGLUTs, respectively. A-D, Astrocytes expressing synapto-pHluorin (raw data). The addition of bafilomycin $A_{1}$ to the astrocytes at rest expressing synapto-pHluorin $(A)$ causes an increase in pHluorin fluorescence $(B, E)$. Quite the contrary, the addition of Rose Bengal to synapto-pHluorin-expressing astrocytes at rest $(C)$ causes decrease of $p H$ luorin fluorescence $(D, E)$. The image in $B$ is acquired after incubation with bafilomycin $A_{1}$ ( $5 \mu \mathrm{m} ; 60 \mathrm{~min}$ ), whereas the image in $D$ is acquired after incubation with Rose Bengal ( $0.5 \mu \mathrm{m} ; 30 \mathrm{~min})$. The pseudocolor scale is a linear representation of the fluorescence intensities ranging from 0 to 255. Changes in synapto-pHluorin fluorescence are expressed as $d F / F o$ (percentage) after background subtraction. Bars represent the means and SEMs. Concentrations $(c)$ and exposure times $(\mathrm{t})$ of pharmacological agents are given in micromolars and minutes, respectively.

(Araque et al., 2000; Pasti et al., 2001). Consistent with previous observations, incubation of astrocytes with bafilomycin $A_{1}$ (5 $\mu \mathrm{M} ; 1 \mathrm{hr}$ ) greatly reduced mechanically induced glutamate release ( $22 \%$ of control; $n=9$; peak response $d F / F o=20 \pm 5 \%$; Fisher's LSD test; $p<0.01$ ) (Fig. $6 D$ ), without significantly affecting $\mathrm{Ca}^{2+}$ elevations (Fig. $6 \mathrm{H} ; n=6$ ).

After demonstration that mechanically induced glutamate release is mediated by exocytosis, we incubated astrocytes with Rose Bengal $(0.5 \mu \mathrm{M} ; 30 \mathrm{~min})$, an inhibitor of vesicular glutamate uptake in synaptic vesicles via allosteric modulation of VGLUTs (Ogita et al., 2001; Schafer et al., 2002). We found that this treatment abolished mechanically induced glutamate release from astrocytes (Fig. $6 C, D$ ) (3\% of control; $n=6 ; d F / F o=2 \pm 2 \%$; Fisher's LSD; $p<0.01$ ) without affecting $\mathrm{Ca}^{2+}$ elevations (Fig. $6 G ; n=7)$. Together, these data indicate that VGLUTs mediate mechanically induced exocytotic release from astrocytes.

Although the presented data are consistent with the notion that glutamate released from astrocyte is stored in acidic compartments that are sensitive to bafilomycin $\mathrm{A}_{1}$ and Rose Bengal, it
A

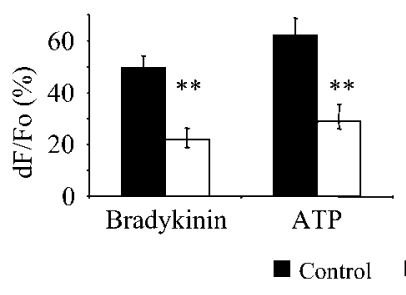

B

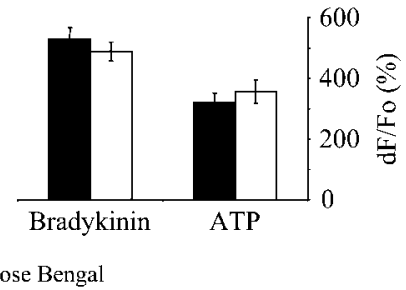

Figure 8. Rose Bengal reduces bradykinin- and ATP-evoked $\mathrm{Ca}^{2+}$-dependent glutamate release from astrocytes. $A$, Stimulation of astrocytes with bath-applied ( $55 \mathrm{sec}$ ) bradykinin ( 90 nм) or ATP $(9 \mu \mathrm{m})$ causes glutamate release (A, black bars) and the increase in internal $\mathrm{Ca}^{2+}$ levels ( $B$, black bars). $A, B$, This agonist-induced glutamate release from astrocytes was greatly reduced when astrocytes were preincubated with Rose Bengal $(0.1 \mu \mathrm{m}$ for $30 \mathrm{~min}$; $A$, open bars), although astrocytic internal $C^{2}{ }^{2+}$ elevations were not affected ( $B$, open bars). Changes in NADH fluorescence, reporting on glutamate release, are shown as $d F / F o$ (percentage) after background subtraction and correction for bleaching. Changes in fluo-3 fluorescence $(B)$, reporting on internal $\mathrm{Ca}^{2+}$ levels, are expressed as $d F / F$ (percentage) after background subtraction. Bars represent the means and SEMs. Asterisks indicate a significant change of measurements compared with the matching control group (Student's $t$ test; ${ }^{* *} p<0.01$ ).

is important to confirm specificity of these pharmacological agents. To address this issue, we transfected the cultured cortical astrocytes using a plasmid encoding for synapto-pHluorin (Sankaranarayanan et al., 2000), a fusion protein that contains a $\mathrm{pH}$ sensitive and fluorescent protein, pHluorin, attached to the $\mathrm{C}$ terminus of synaptobrevin 2. Because pHluorin is attached to the lumenal (intravesicular) portion of synaptobrevin, it is sensing intravesicular $\mathrm{pH}$ with its fluorescence mainly quenched at resting intravesicular $\mathrm{pH}(\sim 5.5)$. However, blockade of V-ATPase using bafilomycin $A_{1}$ can collapse proton gradient, leading to alklinization of intravesicular lumen and increase in pHluorins fluorescence (Sankaranarayanan and Ryan, 2001). Incubation of astrocytes with bafilomycin $\mathrm{A}_{1}(5 \mu \mathrm{M} ; 30$ and $60 \mathrm{~min})$ caused a time-dependent increase in synapto-pHluorin fluorescence (each group, $n=8$; paired $t$ test with Bonferroni adjustment for multiple comparisons; $p<0.01$ ) (Fig. $7 A, B, E$ ). Furthermore, synapto-pHluorin fluorescence showed a punctate pattern consistent with the vesicular nature of exocytosis (Fig. $7 B$ ). Although it has been reported that Rose Bengal, at submicromolar concentrations used in the present study, has a much higher affinity for VGLUTs than for V-ATPase (Ogita et al., 2001), it is necessary to confirm that Rose Bengal does not reduce glutamate release as a result of inhibition of $\mathrm{V}$-ATPase, thereby reducing the proton gradient necessary for glutamate uptake into vesicular lumen, as opposed to its action on allosteric site of VGLUTs. Vesicular proton shunt through VGLUTs reduces the intravascular proton concentration created by V-ATPase. By inhibiting VGLUTs and their proton-shunting activity, Rose Bengal would lead to vesicular acidification and the reduction of synapto-pHluorin fluorescence. Incubation of astrocytes with Rose Bengal $(0.1$ or $0.5 \mu \mathrm{M}$; $30 \mathrm{~min})$ caused a reduction of pHluorin fluorescence $(0.1 \mu \mathrm{M}$, $n=6$; paired $t$ test; $p<0.05 ; 0.5 \mu \mathrm{M}, n=10$; paired $t$ test; $p<$ 0.01 ), consistent with its action on VGLUTs (Fig. 7C-E).

Whereas mechanical stimulation offers direct stimulation of astrocytes without receptor activation and mimics the action of endogenous ligands (Sanzgiri et al., 1999), it is not a physiological stimulus. Consequently, to further study VGLUT-dependent exocytotic glutamate release from astrocytes, we determined the effects of Rose Bengal on astrocytes stimulated by bradykinin (90 $\mathrm{nM} ; 55 \mathrm{sec})$ or ATP ( $9 \mu \mathrm{M} ; 55 \mathrm{sec})$, endogenous ligands known to stimulate $\mathrm{Ca}^{2+}$-dependent glutamate release (Parpura et al., 1994, 1995a; Jeftinija et al., 1997; Jeremic et al., 2001). Both bra- 
dykinin $(n=19)$ and ATP $(n=33)$ caused glutamate release from astrocytes (paired $t$ tests; $p<0.01$ ); release magnitudes were reduced to $44 \%(n=15)$ and $47 \%(n=21)$ of control, respectively (Student's $t$ tests; $p<0.01$ ), when we preincubated astrocytes with Rose Bengal (0.1 $\mu \mathrm{M} ; 30 \mathrm{~min})$ (Fig. $8 \mathrm{~A}$ ). Consistent with preservation of $\mathrm{Ca}^{2+}$ mobilization by bradykinin or ATP, Rose Bengal did not affect ligand-induced $\mathrm{Ca}^{2+}$ elevations in astrocytes (Fig. $8 B$ ) $(n=10$ for bradykinin alone and $n=9$ for bradykinin with Rose Bengal; $n=26$ for ATP alone and $n=18$ for ATP with Rose Bengal; Student's $t$ tests; $p>0.4)$. Thus, three distinct stimuli, mechanical contact, bradykinin, and ATP, can raise intracellular $\mathrm{Ca}^{2+}$ levels and cause glutamate release from astrocytes; release magnitudes can be significantly reduced when we pharmacologically interfered with VGLUTs.

\section{Discussion}

Our findings indicate that the expression of VGLUTs 1 and 2 is not restricted to neurons but that these proteins necessary for glutamate accumulation in synaptic vesicles are also found in astrocytes, as determined by using purified astrocytic culture and Western blots. Immunocytochemisty performed on both cultured and freshly isolated astrocytes reveals punctate pattern of immunoreactivity consistent with the possible role of VGLUTs in exocytotic glutamate release from astrocytes. Furthermore, mechanically, bradykinin-, and ATP-induced glutamate release from astrocytes was greatly reduced when astrocytes were preincubated with Rose Bengal, a broad spectrum modulator of VGLUTs allosteric site, indicating a functional role of VGLUTs in this release.

Interestingly, in freshly isolated astrocytes originating from 1to 2-d-old rat pups, there is a high likelihood that VGLUTs 1, 2, and 3 are co expressed in a single cell (Table 2). Although we did not directly demonstrate the presence of these proteins in single cells, the proportion of cells expressing individual proteins $(86 \%$ for VGLUT 1, 99\% for VGLUT 2, and 74\% for VGLUT 3) supports this inference. However, the probability of dual or triple expression of VGLUTs in individual astrocytes was greatly reduced when we studied astrocytes isolated from 55-d-old animals, as was the proportion of astrocytes expressing individual VGLUTs. Why would individual astrocytes in the developing brains of postnatal animals simultaneously express two or three different VGLUTs? One possible explanation is that the $\mathrm{Ca}^{2+}$ dependent release of glutamate is important for astrocytic roles in modulation of synaptic transmission and that it is necessary to have protein redundancy to ensure astrocytic contribution to the physiology in the CNS. An alternative explanation could be that different VGLUTs have specialized functions in astrocytic glutamate metabolism and/or release. For example, it is entirely possible that VGLUT isoforms are exclusively expressed in a different subpopulation of vesicles within individual astrocytes. These subpopulations of vesicles could represent distinct releasable pools that could control spatiotemporal characteristics of glutamate release. Such a possibility could explain different forms of neuronal responses to glutamate released from astrocytes, including internal $\mathrm{Ca}^{2+}$ increases (Parpura et al., 1994), slowinward currents (Araque et al., 1998a; Parpura and Haydon, 2000), and modulation of spontaneous and action potentialevoked synaptic transmissions (Araque et al., 1998b; Kang et al., 1998). In mature animals, however, VGLUT isoforms 1 and 2 are each expressed in approximately one-third of the astrocytic population (32 and 35\%, respectively). Because VGLUT 3 is expressed in a similar proportion (41\%), it is tempting to suggest that astrocytes could show highly complementary distributions of these three proteins, such as is found in neurons (Herzog et al. 2001; Fremeau et al., 2002; Schafer et al., 2002). An alternative extreme possibility is that only one-third of astrocytes express VGLUTs but all isoforms. Subsequent work will be necessary to resolve these issues. Consequently, it should become possible to selectively manipulate individual VGLUTs in astrocytes to test for their roles in glutamate-mediated astrocyte-neuron signaling in health and disease.

\section{References}

Araque A, Parpura V, Sanzgiri RP, Haydon PG (1998a) Glutamatedependent astrocyte modulation of synaptic transmission between cultured hippocampal neurons. Eur J Neurosci 10:2129-2142.

Araque A, Sanzgiri RP, Parpura V, Haydon PG (1998b) Calcium elevation in astrocytes causes an NMDA receptor-dependent increase in the frequency of miniature synaptic currents in cultured hippocampal neurons. J Neurosci 18:6822-6829.

Araque A, Li N, Doyle RT, Haydon PG (2000) SNARE protein-dependent glutamate release from astrocytes. J Neurosci 20:666-673.

Bai L, Xu H, Collins JF, Ghishan FK (2001) Molecular and functional analysis of a novel neuronal vesicular glutamate transporter. J Biol Chem 276:36764-36769.

Bellocchio EE, Hu H, Pohorille A, Chan J, Pickel VM, Edwards RH (1998) The localization of the brain-specific inorganic phosphate transporter suggests a specific presynaptic role in glutamatergic transmission. J Neurosci 18:8648-8659.

Bezzi P, Carmignoto G, Pasti L, Vesce S, Rossi D, Rizzini BL, Pozzan T, Volterra A (1998) Prostaglandins stimulate calcium-dependent glutamate release in astrocytes. Nature 391:281-285.

Bezzi P, Domercq M, Brambilla L, Galli R, Schols D, De Clercq E, Vescovi A, Bagetta G, Kollias G, Meldolesi J, Volterra A (2001) CXCR4-activated astrocyte glutamate release via TNFalpha: amplification by microglia triggers neurotoxicity. Nat Neurosci 4:702-710.

Bowman EJ, Siebers A, Altendorf K (1988) Bafilomycins: a class of inhibitors of membrane ATPases from microorganisms, animal cells, and plant cells. Proc Natl Acad Sci USA 85:7972-7976.

Coco S, Calegari F, Pravettoni E, Pozzi D, Taverna E, Rosa P, Matteoli M, Verderio C (2003) Storage and release of ATP from astrocytes in culture. J Biol Chem 278:1354-1362.

Dani JW, Chernjavsky A, Smith SJ (1992) Neuronal activity triggers calcium waves in hippocampal astrocyte networks. Neuron 8:429-440.

Dieck ST, Heuer H, Ehrchen J, Otto C, Bauer K (1999) The peptide transporter PepT2 is expressed in rat brain and mediates the accumulation of the fluorescent dipeptide derivative beta-Ala-Lys-Nepsilon-AMCA in astrocytes. Glia 25:10-20.

Fremeau Jr RT, Troyer MD, Pahner I, Nygaard GO, Tran CH, Reimer RJ, Bellocchio EE, Fortin D, Storm-Mathisen J, Edwards RH (2001) The expression of vesicular glutamate transporters defines two classes of excitatory synapse. Neuron 31:247-260.

Fremeau Jr RT, Burman J, Qureshi T, Tran CH, Proctor J, Johnson J, Zhang H, Sulzer D, Copenhagen DR, Storm-Mathisen J, Reimer RJ, Chaudhry FA, Edwards RH (2002) The identification of vesicular glutamate transporter 3 suggests novel modes of signaling by glutamate. Proc Natl Acad Sci USA 99:14488-14493.

Fujiyama F, Furuta T, Kaneko T (2001) Immunocytochemical localization of candidates for vesicular glutamate transporters in the rat cerebral cortex. J Comp Neurol 435:379-387.

Gras C, Herzog E, Bellenchi GC, Bernard V, Ravassard P, Pohl M, Gasnier B, Giros B, El Mestikawy S (2002) A third vesicular glutamate transporter expressed by cholinergic and serotoninergic neurons. J Neurosci 22:5442-5451.

Hepp R, Perraut M, Chasserot-Golaz S, Galli T, Aunis D, Langley K, Grant NJ (1999) Cultured glial cells express the SNAP-25 analogue SNAP-23. Glia 27:181-187.

Herzog E, Bellenchi GC, Gras C, Bernard V, Ravassard P, Bedet C, Gasnier B, Giros B, El Mestikawy S (2001) The existence of a second vesicular glutamate transporter specifies subpopulations of glutamatergic neurons. J Neurosci 21:RC181(1-6).

Hisano S, Hoshi K, Ikeda Y, Maruyama D, Kanemoto M, Ichijo H, Kojima I, Takeda J, Nogami H (2000) Regional expression of a gene encoding a 
neuron-specific $\mathrm{Na}(+)$-dependent inorganic phosphate cotransporter (DNPI) in the rat forebrain. Brain Res Mol Brain Res 83:34-43.

Huttner WB, Schiebler W, Greengard P, De Camilli P (1983) Synapsin I (protein I), a nerve terminal-specific phosphoprotein. III. Its association with synaptic vesicles studied in a highly purified synaptic vesicle preparation. J Cell Biol 96:1374-1388.

Innocenti B, Parpura V, Haydon PG (2000) Imaging extracellular waves of glutamate during calcium signaling in cultured astrocytes. J Neurosci 20:1800-1808.

Jeftinija SD, Jeftinija KV, Stefanovic G (1997) Cultured astrocytes express proteins involved in vesicular glutamate release. Brain Res 750:41-47.

Jeremic A, Jeftinija K, Stevanovic J, Glavaski A, Jeftinija S (2001) ATP stimulates calcium-dependent glutamate release from cultured astrocytes. J Neurochem 77:664-675.

Kaneko T, Fuijyama F, Hioki H (2002) Immunohistochemical localization of candidates for vesicular glutamate transporters in the rat brain. J Comp Neurol 444:39-62.

Kang J, Jiang L, Goldman SA, Nedergaard M (1998) Astrocyte-mediated potentiation of inhibitory synaptic transmission. Nat Neurosci 1:683-692.

Kimelberg HK (2001) Glia-neuronal culture models-do we need to change the paradigms? Trends Neurosci 24:205-206.

Kimelberg HK, Schools GP, Cai Z, Zhou M (2000a) Freshly isolated astrocyte (FIA) preparations: a useful single cell system for studying astrocyte properties. J Neurosci Res 61:577-587.

Kimelberg HK, Cai Z, Schools G, Zhou M (2000b) Acutely isolated astrocytes as models to probe astrocyte functions. Neurochem Int 36:359-367.

Krzan M, Stenovec M, Kreft M, Pangrsic T, Grilc S, Haydon PG, Zorec R (2003) Calcium-dependent exocytosis of atrial natriuretic peptide from astrocytes. J Neurosci 23:1580-1583.

Latour I, Hamid J, Beedle AM, Zamponi GW, Macvicar BA (2003) Expression of voltage-gated $\mathrm{Ca} 2+$ channel subtypes in cultured astrocytes. Glia 41:347-353.

Maienschein V, Marxen M, Volknandt W, Zimmermann H (1999) A plethora of presynaptic proteins associated with ATP-storing organelles in cultured astrocytes. Glia 26:233-244.

McCarthy KD, deVellis J (1980) Preparation of separate astroglial and oligodendroglial cell cultures from rat cerebral tissue. J Cell Biol 85:890-902.

Nedergaard M (1994) Direct signaling from astrocytes to neurons in cultures of mammalian brain cells. Science 263:1768-1771.

Ni B, Rosteck Jr PR, Nadi NS, Paul SM (1994) Cloning and expression of a cDNA encoding a brain-specific $\mathrm{Na}(+)$-dependent inorganic phosphate cotransporter. Proc Natl Acad Sci USA 91:5607-5611.

Ni B, Wu X, Yan GM, Wang J, Paul SM (1995) Regional expression and cellular localization of the $\mathrm{Na}(+)$-dependent inorganic phosphate cotransporter of rat brain. J Neurosci 15:5789-5799.

Ni Y, Sunjara V, Parpura V (2003) Expression of vesicular glutamate transporters in cultured astrocytes. FASEB J [Suppl] 17:A457.
Ogita K, Hirata K, Bole DG, Yoshida S, Tamura Y, Leckenby AM, Ueda T (2001) Inhibition of vesicular glutamate storage and exocytotic release by Rose Bengal. J Neurochem 77:34-42.

Parpura V, Haydon PG (2000) Physiological astrocytic calcium levels stimulate glutamate release to modulate adjacent neurons. Proc Natl Acad Sci USA 97:8629-8634.

Parpura V, Basarsky TA, Liu F, Jeftinija K, Jeftinija S, Haydon PG (1994) Glutamate-mediated astrocyte-neuron signalling. Nature 369:744-747.

Parpura V, Liu F, Brethorst S, Jeftinija K, Jeftinija S, Haydon PG (1995a) Alpha-latrotoxin stimulates glutamate release from cortical astrocytes in cell culture. FEBS Lett 360:266-270.

Parpura V, Fang Y, Basarsky T, Jahn R, Haydon PG (1995b) Expression of synaptobrevin II, cellubrevin and syntaxin but not SNAP-25 in cultured astrocytes. FEBS Lett 377:489-492.

Pasti L, Zonta M, Pozzan T, Vicini S, Carmignoto G (2001) Cytosolic calcium oscillations in astrocytes may regulate exocytotic release of glutamate. J Neurosci 21:477-484.

Peters A, Palay SL, Webster HD (1991) The fine structure of the nervous system, Ed 3. New York: Oxford UP.

Sakata-Haga H, Kanemoto M, Maruyama D, Hoshi K, Mogi K, Narita M, Okado N, Ikeda Y, Nogami H, Fukui Y, Kojima I, Takeda J, Hisano S (2001) Differential localization and colocalization of two neuron-types of sodium-dependent inorganic phosphate cotransporters in rat forebrain. Brain Res 902:143-155.

Sankaranarayanan S, Ryan TA (2001) Calcium accelerates endocytosis of vSNAREs at hippocampal synapses. Nat Neurosci 4:129-136.

Sankaranarayanan S, De Angelis D, Rothman JE, Ryan TA (2000) The use of pHluorins for optical measurements of presynaptic activity. Biophys J 79:2199-2208.

Sanzgiri RP, Araque A, Haydon PG (1999) Prostaglandin E(2) stimulates glutamate receptor-dependent astrocyte neuromodulation in cultured hippocampal cells. J Neurobiol 41:221-229.

Schafer MK, Varoqui H, Defamie N, Weihe E, Erickson JD (2002) Molecular cloning and functional identification of mouse vesicular glutamate transporter 3 and its expression in subsets of novel excitatory neurons. J Biol Chem 277:50734-50748.

Takamori S, Rhee JS, Rosenmund C, Jahn R (2001) Identification of differentiation-associated brain-specific phosphate transporter as a second vesicular glutamate transporter (VGLUT2). J Neurosci 21:RC182(1-6).

Varoqui H, Schafer MK, Zhu H, Weihe E, Erickson JD (2002) Identification of the differentiation-associated $\mathrm{Na}+/ \mathrm{PI}$ transporter as a novel vesicular glutamate transporter expressed in a distinct set of glutamatergic synapses. J Neurosci 22:142-155.

Zhou M, Kimelberg HK (2000) Freshly isolated astrocytes from rat hippocampus show two distinct current patterns and different $[\mathrm{K}(+)](\mathrm{o})$ uptake capabilities. J Neurophysiol 84:2746-2757. 